\title{
CLIMATE-NEUTRAL AND SMART CITIES: A EUROPEAN POLICIES' OVERVIEW
}

\author{
ANDREA BOERI, DANILA LONGO \& MARCO PALMA \\ Department of Architecture, University of Bologna, Italy
}

\begin{abstract}
Cities are increasingly defined as one of the most important actors in the transition to a climate-neutral Europe. The reasons are multiple, and some of them are the increasing number of inhabitants and the demographic trends; the percentage of emissions produced by the urban areas; the innovation potential, thanks to the concentration of creativity and knowledge; the political dimension that helps in involving the citizens; the economical role and the fact that cities and towns are transport networks' hubs. Recognizing this crucial role, the European Union is updating its own policies on the matter, promoting challenging strategies as the Horizon Europe Mission on "Climate-neutral and Smart Cities". This article analyses the European policies and strategies aimed at tackling the climate change in the urban areas. They are making the cities the forefront where to speed up the transition and promote flagship actions able to pave the way for reaching the European Green Deal goals. Moving from the main policies, this article investigates the overall ratio behind them and presents the tools and the actions promoted by the European Commission to support the local authorities in recognizing and facing the challenge, which is at the very core of the New Generation EU programme and a key enabler in designing the post-Covid Europe. On the other hand, this article briefly presents the main activities that cities are expected to develop in the next decade in order to fully contribute to the European ambition to be the first carbon-neutral continent on the planet by 2050 .

Keywords: cities, citizens engagement, climate change, tools for transition, policies.
\end{abstract}

\section{INTRODUCTION}

Since the beginning of 2020, we are experiencing a dramatic pandemic with millions of deaths and extreme negative social and economic consequences. Our daily life is unexpectedly radically changed, and all those elements have demonstrated to the humanity how fragile is the societal systems we assumed to be untouchable.

However, many scientists warn us about the fact that the consequences and changes caused by Covid-19 are minor in comparison to what we may see in the next decades due to the global warming and the climate change. Limiting our focus on direct health related risks, the Intergovernmental Panel on Climate Change (IPCC) underlines that "any increase in global warming is projected to affect human health, with primarily negative consequences and risks from some vector-borne diseases, such as malaria and dengue fever, are projected to increase with warming from $1.5^{\circ} \mathrm{C}$ to $2^{\circ} \mathrm{C}$, including potential shifts in their geographic range" [1].

International efforts to limit the temperature increase are often judged by experts and environmental associations and activists as contradictory since declarations of commitment are not followed by concrete action plans. The Sustainable Developments Goals (SDGs) adopted by all United Nations Member States in 2015 sets the shared blueprint of the 2030 Agenda for Sustainable Development. This Agenda, together with the Paris Agreement, is today the most comprehensive international agreement on the issue. However, both these documents delegate member states in adopting adequate measures to contribute to the global effort, without setting a clear and common action plan. 
In the last years, the European Union proposed itself as the global leader of the climate transition, adopting ambitious policies and setting goals and milestones to reach the climateneutrality within the 2050 .

In this context, cities are assuming a main role. On one hand, urban areas are responsible of $70 \%$ of the global $\mathrm{CO}_{2}$ emissions and two-thirds of the energy consumption. In the European Countries, "the building sector is the single largest energy consumer (40\%), the largest raw materials user $(50 \%$ of the extracted materials) and thus one of the largest greenhouse gas emitters (36\% of energy-related direct and indirect emissions) [2]. As stated by the European Mission Board on Climate-neutral and smart cities, "cities cover about 3\% of the land on Earth, yet they produce about $72 \%$ of all global greenhouse gas emissions" [3]. Considering that "the population residing in urban areas is projected to reach $83.7 \%$ in 2050" [4], it is clear how crucial it is to radically transform our cities.

On the other hand, there is an increasing number of cities adopting plans and strategies for facing climate change. European Eurobarometer has measured the growing concern of European citizens, underlining that "awareness of climate change and the need for action is increasingly widespread and one of the largest demonstrations of this in recent times is the youth movement for climate that has garnered strong support in countries around the word" [5].

Municipalities and local authorities are the first level of governance, with the stronger relation with citizens, and it partially explains local efforts. Furthermore, many cities are facing growing issues related to climate change, as floods, heat islands, pollution, extreme weather events, and this encourages them to act. But "cities are also the melting pot where decarbonization strategies for energy, transport, mobility and even industry and agriculture coexist and intersect" [6]. Considering all these elements together, we can assume the urban areas are one of the crucial actors in facing the climate emergency and putting in place ambitious policies and adequate solutions.

The European Commission recognizes this role through its policy documents. In the last Multiannual Financial Framework there are increased resources and activities devoted in supporting cities willing to promote and realize demonstrators, governance reforms and structural transition actions toward a net zero greenhouse gas emissions society within 2050 .

\section{FACING CLIMATE CHANGE IN URBAN AREAS: \\ THE EUROPEAN GREEN DEAL AND THE MAIN RELATED POLICIES}

The European commitment to climate change is growing every year more. A complex policies review is currently in place to align different legislations and regulations to the political objectives set by the European Commission and the Member States. New policies, strategies and regulations have been adopted as well, and the already existing legislations will be updated for guaranteeing a coherent scenario. The core of this approach set by the European Commission is the new European Green Deal.

$92 \%$ of European citizens "agree that greenhouse gas emissions should be reduced to a minimum while offsetting the remaining emissions, in order to make the EU economy climate neutral by 2050" [7]. It seems that the communication of the European Commission establishing "a European strategic long-term vision for a prosperous, modern, competitive and climate neutral economy" [8] benefits a widespread consensus among the European citizens.

The vision establishes a precise goal to be reached within the 2050: making Europe the first carbon-neutral continent on the planet. This ambitious target is rooted on the scientific evidence that underlines the need to face global warming containing the temperature increase 
within $1.5^{\circ} \mathrm{C}$ above pre-industrial levels. However, it is as well a development strategy, betting on climate neutrality as a fundamental pillar to guarantee Europe's prosperity.

According to this point of view, European Commission estimates that the EU economy will "more than double by 2050 compared to 1990 even as it fully decarbonized. A trajectory compatible with net-zero greenhouse gas emissions, together with a coherent enabling framework, is expected to have a moderate to positive impact on GDP with estimated benefits of up to $2 \%$ of GDP by 2050 compared to the baseline. Very important, these estimates do not include the benefit of avoided damage of climate change and related adaptation costs" [8].

The strategy "set[s] the direction of travel for the EU climate and energy policy, and frames what the EU considers as its long-term contribution to achieving the Paris Agreement temperature objectives in line with UN Sustainable Development Goals" [8]. The plan describes a holistic approach, and, for that reason, it does not promote new policies, but strives for influencing both the European and the national strategies, laws, and rules. The first legislations and regulations included in the European Green Deal are the Climate Law, the Climate Pact, the new European Strategies on Climate Adaptation, and the 2030 Climate Target Plan, which are presented in the following sections.

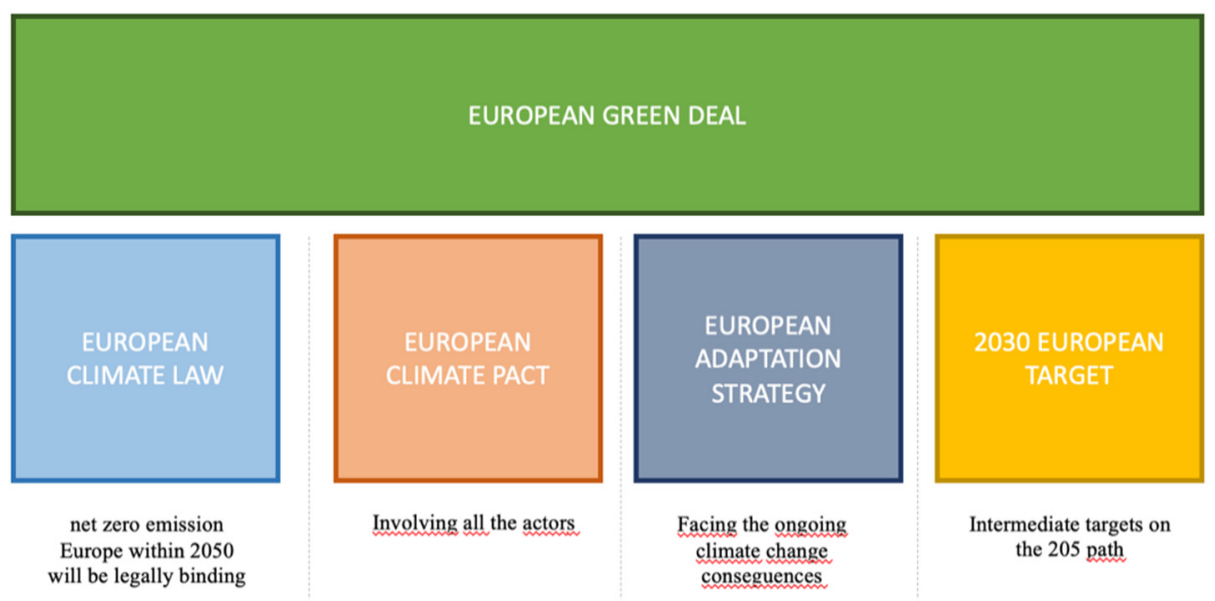

Figure 1: European green deal, regulations, and policies.

While active citizens engagement is at the base of the strategy, different sub-fields of intervention are energy efficiency, renewable energy, mobility, industry, infrastructures and agriculture.

In the framework of this long-term vision, citizens - who are requested to "embrace change, get engaged and experience it as beneficial for their lives and that of their children" [8], but also to play a key role as consumers - and cities have a crucial role. The European Commission recognizes that cities are already laboratories for transformative and sustainable solutions, underlining that many of the needed transformations can take place in the urban areas.

\subsection{The climate law}

The European Climate Law proposed by the Commission represents the legislative face of the European commitment in facing climate change. It defines roles and instruments for 
implementing the European Green Deal's principles, setting the path for both realizing the transition and monitoring it.

While we are writing this article, the Climate Law is still under negotiation between the European Commission, the Member States' Council, and the European Parliament. However, some agreements have already been reached and the main points which will characterize the law are already set down.

Thanks to the law, the objective of a net zero emission Europe within 2050 will be legally binding. Furthermore, intermediate targets will be established and the first refers to 2030 when Europe aims at reaching the target of reducing the greenhouse gas emissions by at least $55 \%$ compared to the 1990's levels. Moreover, the Commission will monitor if and how national measures will be in line with the European targets, and in case the targets are not met, the Member States will be obliged to take in due account the Commission's recommendations.

Moreover "the Commission proposes the adoption of a 2030-2050 EU-wide trajectory for greenhouse gas emission reductions, to measure progress and give predictability to public authorities, businesses and citizens" [9].

\subsection{The climate pact}

"We have not moved fast enough to prevent irreversible and catastrophic climate change" [10]: this is the main reason why, among the other policies, the Commission has decided to promote a European Climate Pact aiming at bringing together "regions, local communities, civil society, industry and schools [that] will design and commit to a set of pledges to bring about a change in behaviour, from the individual to the largest multinational" [11].

The Pact is not strictly a policy nor a strategy or a funding tool. On the contrary, it reflects the confidence about the essential role played by non-institutional actors in facing the climate change emergency. It is the reason which pushes the European Commission in looking into new inclusive and participative paths able to produce a huge impact on the European society.

Through the European Climate Pact, the Commission tries to actively involve different stakeholders - from citizens to bigger organizations - to:

- create a network of those already active in climate action and attract interest of those 'indifferent' or 'hard to reach', with the general objective of raising awareness.

- Engage with citizens and stakeholders, in order to spread potential solutions and best practices: the Climate Pact Ambassadors, who are volunteers endorsed by the European Commission, are at the core of this type of activity that foresee climate literacy and education programmes as well.

- Support citizens, local authorities, and other stakeholders in implementing actions, particularly thanks to digital tools aimed at helping citizen dialogues and spreading information through a Knowledge Hub.

Although the Climate Pact is designed to operate on all the different fields that influence climate change, four beginning topics have been identified: green areas, green mobility, green buildings, and green skills. These topics have been chosen for two main reasons: on the one hand, they are the most prioritized items from the European Union; on the other hand, policies, support mechanisms and European strategies on these topics are already in place and need to be boosted. 


\subsection{The new European strategy on adaptation to climate change}

"Halting all greenhouse gas emissions would still not prevent the climate impacts that are already occurring" [12]. The European Strategy on Adaptation to Climate Change works on the other face of the coin: recognizing the fact that climate change is already ongoing - and the consequences are inevitable - the strategy emphasizes the crucial role of adaptation for reaching the European 2050's goals.

Knowledge and digitalization are at the core of this strategy. Sharing information and facilitate a climate assessment decision-making are two crucial points in the adaptation's path. By this means, the Climate Adapt Platform is at the same time a strategic European tool for disseminating knowledge and information and for promoting a European climate and health observatory. The platform collects information and data from different sources - as Copernicus - and contributors.

The local dimension is considered crucial for adaptation. For that reason, the strategy promotes two main pillars: on the one hand, it wants to foster a just and fair way for spreading adaptation measures; that means both supporting local authorities in implementing actions and reskilling workers through tailored educational programmes. On the other hand, the strategy aims at integrating climate resilience in national fiscal frameworks: this will push the development of tools for measuring the potential impact of climate-related risks on public finance and prevent the fiscal impact of climate-related events which may have a negative impact on economic growth.

Concerning the type of actions, nature-based solutions (NBS) on a larger scale are considered an important contributor for reaching multiple Green Deal objectives. They are not only useful for improving the resilience but are also considered as a solution for carbon removals. For that reason, the Commission aims at leveraging investment on this kind of blue and green infrastructure, which involve the urban areas as well. Regarding infrastructures, the strategy also underlines that "extreme weather and long-lasting climatic changes can damage buildings and their mitigation potential e.g., solar panels or thermal insulation [...]. However, buildings can also contribute to large-scale adaptation" [12].

\subsection{The 2030 climate target plan}

In September 2020, the European Commission proposed new climate targets to be reached within the 2030, underling that "the climate crisis remains the defining challenge of our time" [13]. The Commission bases the proposal on the evidence that "in 2019 EU emissions, including removals, were down by an estimated $25 \%$ compared to 1990 , while over the same period the economy has grown by $62 \%$. This proves that we can tackle climate change and ensure sustained economic growth" [13]. On the other hand, measures foreseen by the existing legislative tools are non-enough in order to guarantee a secure, well-planned and sustainable path towards making Europe the first continent carbon-neutral within the 2050 . For these reasons, a new and more ambitious target has been set up, and the Commission proposed to reduce the overall $\mathrm{CO}_{2}$ emission by $55 \%$ within 2030, compared to 1990 .

Reaching this goal means developing multi-sector actions, intervening also in areas in which to reduce emissions has been proved to be harder. From this point of view, particular challenges exist on transport, agriculture, and buildings.

The document set targets on different fields, like building and power generation, renewable energy, heating and cooling, buildings renovation, transport, industry. 


\section{TRANSFORMING THE CITIES: THE MAIN POLICIES}

Specific policies have been established over the years to support local authorities in enhancing their actions on different fields. During the last years, the focus has been partially shifted on issues related to climate change, considering the actions fields from mitigation and adaptation to inclusiveness and awareness. How to govern the processes is a focal point as well. This section describes the main European policies aimed at enforcing the local governments' role in guiding the transition.

\subsection{The new Leipzig charter}

The Leipzig Chapter has been adopted by the European Ministers responsible on Urban Matters in 2007 and refocused in November 2020 with the aim of providing a policy framework to adequately respond the challenges underlined by the 2030 Agenda for Sustainable Developments, the Paris Agreement, and the European Commission's Green Deal. The document sets the strategic principles of a good urban governance.

It recognizes cities as enabler of cultural social, ecologic, and economic interaction, underling that culture is at the core of any sustainable urban development. According to this point of view, the chapter remembers that "most cities are unique, historically grown centers of outstanding cultural value shaping Europe's urban heritage and the identity of its citizens" [14]. For the same reasons, cities are places of pluralism, creativity and solidarity and laboratories for new forms of problem solving and test beds for social innovation.

The chapter identifies three spatial levels that need to be activated for pursuing the common good: the neighbourhood, where it is possible to set out actions aimed at community building and inclusiveness; the local authorities, which are the intermediate bodies linking the small-scale neighbourhoods with the wider functional areas; this last dimension is defined as the complex network of functional interdependencies and partnerships where a resilient development can take place. This implies a strong coordination and collaboration between town and cities and their surrounding suburban and rural areas.

Three different action areas characterize the urban transformation's concept, which has to integrate social, ecological and economic dimensions of the sustainable development: the just city, where no-one has left behind; the green city, where actions on green spaces, energy, building efficiency, biodiversity, green and blue infrastructures, natural-based solutions, mobility and services are designed and implemented in a coordinated and synergic manner; the productive city, promoting especially new small sustainable and local business, lowemission manufacturing and urban agriculture. Two are the main enablers: the digitalization and high-quality public spaces allowing people to interact, exchange and integrate into the society.

For reaching these goals, the chapter set a list of cities needs as well: clear and coordinated legal framework conditions; investment capacities; adequately skilled employees; steerability and shaping of infrastructures.

\subsection{The New European Bauhaus initiative}

"The New European Bauhaus (NEB) initiative is a think-do tank. A design lab, accelerator, and network at the same time. A creative and interdisciplinary movement, convening a space of encounter to recuperate and revisit sustainable practices forms, empower the most inspiring practices of today, and design future ways of living, at the crossroads between art, culture and science" [15]. This is the brief definition the European Commission gives about this new initiative strongly endorsed by Ursula Von Der Leyen at the beginning of 2021. In 
a video [16], the President of the European Commission said that the NEB is "a project of hope" that designs "how we want to live after the pandemic while respecting the planet and protecting our environment". The initiative has been presented by her as "an inclusive and collective process" engaging "professional architects, citizens, CEOs of big companies and innovative start-ups" bringing their ideas together.

The keywords of the initiative are creativity, innovation, imagination design. The European Commission aims at fostering the transition requested by the European Green Deal connecting the actions required for facing the climate change with improvement of the citizens' quality of life. Green and digital transitions are therefore mutually connected, and the expectations are to push transformations in the market and in the behaviours as well, focusing beyond buildings.

The New European Bauhaus has been structured in 3 different phases:

- The Design phase, with the aim to connect with existing initiatives and projects to see where and how the NEB can accelerate, concretize and materialize good ideas.

- The Delivery phase, that aims at learning and benefit from five NEB pilots selected through a call for proposals and open to all the design phase's participants ("community of practice").

- The Dissemination phase, with the aim to diffuse good ideas and concepts to a broader audience in Europe and beyond.

\subsection{Involving the local authorities: Covenant of Mayors and Green City accord}

The Covenant of Mayors is one of the longest running European initiatives related to sustainability and cities. Launched in 2018 by the European Commission as a tool for promoting energy efficiency and energy transition, it has been updated in 2015 as the Covenant of Mayors for Climate and Energy, after being merged with the twin initiative Mayors Adapt. Since 2016 the initiative joins forces with the Compact of Mayors, the global initiative launched by the United Nations in 2014.

It involves cities on a voluntary basis, committing the local authorities to a shared vision and common goals. With the latest updates, the initiative has aligned its goals with the European Green Deal, paving the way for reaching the 2050's objectives.

"In order to translate their political commitment into practical measures and projects, Covenant signatories commit to submitting, within two years following the date of the local council decision, a Sustainable Energy and Climate Action Plan (SECAP) outlining the key actions they plan to undertake. The plan features a Baseline Emission Inventory to track mitigation actions and a Climate Risks and Vulnerability Assessment" [17]. After the approval the local plans are included in the initiative and the signatories commit themselves in monitoring the progresses.

Nowadays, more than 10,000 local administrations around Europe participate in the initiative, involving more than 334,832,000 European citizens. The Covenant of Mayors represents the most recognized European initiative that supports and coordinates the Municipalities in planning how to mitigate and adapt to climate change, but the participation is different within Member States.

The Green City Network [18] has been launched by the Commission in 2021, focuses on environmental management and involving cities on five main goals which the signatories want to achieve by 2030: improving the air quality; promoting water use efficiency; enhancing urban biodiversity; advancing circular economy and reducing noise pollution. The 
document does not set any baseline or target, which are both delegated to the signatory authorities which are expected to go beyond the minimum requirement set by EU legislation.

\section{FINANCING THE TRANSITION: THE MAIN EUROPEAN TOOLS}

Financial aspects are crucial for implementing policies and developing transformative actions that will radically change the urban landscape and lifestyles as well. In this section, we focus on the main financing tools provided by the European Commission, deepening those that are expected to provide the most disruptive innovations.

4.1 The financing programmes: Horizon Europe, Life and the new European Urban Initiative post 2020

We are currently at the beginning of the new Multiannual Financial Framework adopted by the European Parliament, EU Member States in the Council, and the European Commission on 10 November 2020. The agreement includes the Recovery Plan for facing the pandemic and its consequences, and the long-term budget for 2021-2027 consists of $€ 1.074$ trillion.

The Multiannual Financial Framework covers different funding programmes which focus on a multitude of topics and challenges. The main headings are:

- $\quad$ Single Market, Innovation and Digital

- Cohesion, Resilience and Values

- Natural Resources and Environment

- Migration and Border Management

- Security and Defence

- Neighbourhood and the Word

- European Public Administration

At least $30 \%$ of the overall budget will be spent on projects and activities contributing to facing the climate change. Certainly, the climate transition - which, on the European documents, need to be fair, inclusive, and just - will be one of the goals of every European Funding Programmes, and each of them will face the challenge from different points of view. However, two programmes will pave the path for the transition: Horizon Europe and Life Programme.

Horizon Europe is the framework programme for research and innovation, the one with the biggest budget in the European context. Climate change is a cross-cutting issue, characterizing all the three programme pillars. However, specific destinations and topics are included especially in pillar two. Concerning the cities' role, a specific section is included in the cluster 5, destination 2, where topics that aim at facing climate change in urban areas are proposed in the section "Communities and cities". Furthermore, following Professor Mazzuccato's proposal, Horizon Europe includes Missions defined as "commitments to solve some of the greatest challenges facing our world" [19]. One of these Missions is devoted to promoting climate-neutral and smart cities (see Section 4.2).

Life is the European funding programme historically devoted to preserve the environment, the nature, and the biodiversity. Since 2014, it has partially changed its own mission, including climate action as a sub-programme.

Towns and cities can find financial support also through the new European Urban Initiative post 2020, rooted on the experience of the programme Urban Innovative Actions, which have had five thematic calls in the period 2014-2020. The new initiative is structured on three main strands: 
- capacity-building, with the aim of fostering a community of practice able to support cities around Europe in accelerating the transition.

- innovative actions, with which experimentation in the area of sustainable urban development focusing on innovation and governance can be carried out.

- knowledge dissemination, sharing data and information to support a better policy design.

This initiative is programmed under the European Regional Development Fund (ERDF).

\subsection{The Mission "Climate-neutral and smart cities"}

"The introduction of a Climate City Mission is a radical new way of achieving climate neutrality - and of doing so faster, by 2030 . The Mission aims to promote system innovation across the value chain of city investment, targeting multiple sectors such as governance, transport, energy, construction, and recycling, with support from powerful digital technologies. As such, it requires a change in regulations, approaches and instruments combined with the willingness to go beyond existing schemes and habits. The Mission also demands a change of attitude towards practical aspects of implementation, but also as concerns people and organizations working together: citizens, local governments, central and regional governments, and European institutions. We expect citizens, city administrations and political leaders to show commitment, imagination and determination" [20].

The role the urban areas are gathering is well demonstrated by the Mission ' 100 climateneutral cities by 2030 - by and for the citizens. If in the past cities were the location where deploying actions, this new approach defines them as one of the main actors of the transition. The focus changes and moves from technologies to governance. Even though innovation in different fields is still required, the process on how the transformation can be implemented is considered as the real potentially disruptive element for reaching the 2050 targets.

The most important innovation introduced by the Mission's approach is considering the governance as the key-enabler for any transformation. Focusing on how a zero-emission society can be reached, the Mission introduces two different but complementary levels: the first is the local level, where citizens need to be actively involved. That is not just a democracy issue: the inhabitants are at the same time citizens - having the right to participate in the transformation of the place where they live - and users, producers, consumers, and owners. It means that they are key actors without whom it is not possible to reach the goal. In other words, the concept of democracy is itself moving up from the delegation towards new decision-making forms in which "citizen engagement has to be inclusive, deliberative and influential" [21].

The second level is the one that includes different institutional actors. In the last decades, local authorities where more beneficiaries than actors of the European policies. They could receive funds for implementing actions, but the institutions involved in defining the priorities where mainly the regional and national governments. The Mission's approach, on the contrary, poses the cities at the very center\# of the priorities' definition. It happens for two main reasons: on one side, differences between cities in societal, environmental, economic, and urban dimensions are recognized and solutions need to be designed taking into account these aspects. Starting from this evidence, the Mission asks the cities to self-assess their readiness and design specific and targeted solutions. On the other side, the Mission recognizes the interconnections between local, regional, national, and European policies, calling for an integrate and multi-level approach. By this way, local authorities become the nodal point of a network of institutional relations that involve all the different actors, connecting their actions with the regional and national strategies for carbon neutrality by 
2050 and assuming that the measures taken should not be physically unconnected or stop working at the borders of the cities.

The main tool foreseen by the Mission as underpinning these characteristics is the Climate City Contract that should be the result of a co-creation's approach involving citizens, local communities, stakeholders, and relevant institutions. Ideally, the contract has to be signed by all institutions involved in the policies, both at the local, regional, national and European level.

The climate contract includes the goals and the targets, specifies the strategy and the action plan for transition, and identifies stakeholders and responsibilities.

\section{POLICIES ANALYSIS AND SHORT CONCLUSIONS}

The European Commission gives great emphasis on the potential role Europe can play in the global context for facing the climate change and the increasing importance of urban areas in developing actions in line with the ambitious goals which have been set.

Reading the Commissioners' statements and the principles set through regulations and strategies, we can find a comprehensive approach that covers many aspects related to the complexity of the challenge: air, soil, water, human activities, energy, buildings, mobility, and many other topics are part of documents as the European Green Deal. At the same time, we can find an increasing coordination between different strategies and policies, which refer to the same challenges covering different aspects. The funding instruments seem to be aligned with the strategic propositions; however, implementation will be crucial to understand the impacts of the actions.

Participation, civic engagement, and empowerment are often quoted in these documents. There is no doubt about the importance of involving citizens in changing our cities and our behaviours. However, it is still ambiguous which kind of participatory tools the European Union will set out in the following years. In the last months consultation appeared as the most used instrument by the Commission, and during the introduction of new policies like the European Green Deal and the New European Bauhaus, the European Commission asked citizens and stakeholders to share opinions and ideas. However, this may not be enough to ensure an increasing role to European citizens in defining policies, investments, and actions for facing climate change. Indeed, the decision process remains unchanged, and the tools introduced seems to be more like a kind of polls than new and innovative participatory paths.

Following this argumentation, the choice of the stakeholders to be at the core of the process will make a huge difference. In the last decades Europe has often been the space in which lobbies and multi-national powers strongly influenced the decision-making process whereas civic organizations and social movements had a very marginal voice. The kind of balance of power to be set out in the following years will define the strategy underpinning the climate transition, the selected technologies, and the social solutions. The Europe we will live in 2050 will be the results of this balance.

More in general, it is still unclear how successfully demonstrators and pilot actions promoted and funded by the policies presented in this article will be replicated in towns and cities. From this point of view, a clear European vision appears to be undeveloped, and the financing tools seem to be dedicated at promoting single best practices and flagship initiatives more than finding structural solutions that involve all the Member States. Moreover, how general objectives and challenging goals set out by the Commission for the European continent will be translated into national and local concrete actions and investments is an issue that the documents analysed in this article do not present in depth. Thinking about subsidiarity, this may seem as a good strategy; however, strong differences between Member States may negatively affect the final results, preventing Europe to reach the common goals. 
How European strategies are transposed into national legislations is still problematic and represents a threat to the strategies' implementation.

Following this point, the European approach seems to still lack capacity building and technical support tools. Europe has dozens of big cities with efficient administrative structures, but we cannot forget the hundreds of thousands of small towns and villages, which are the core of the European urban landscape. These ones do not often have structured internal offices able to develop programmes and projects for implementing the European projects. From that point of view, new technical assistance instruments and dedicated financing initiatives seems to be crucial to spread best practices and involve all European citizens - and not only those living in the biggest and richest cities - in a just transition toward a net zero emissions Europe.

In conclusion, declarations and actions are still far from each other. The 2050 European vision is more a development plan than a social and ecological answer to the crisis; furthermore, following the Arnstein's Ladder [22] on the degrees of citizen participation, the citizens' empowerment seems more a tokenism than a real and effective citizens control on policies and choices. Member States still have the final world about how to implement the policies described in this article. Municipalities are often more engaged than national authorities in facing climate crisis, but without a strong coordination and multilevel synergies, the challenging goals the European Union wants to reach are not achievable. Cities are without any doubt key players in facing global warming and involving the inhabitants in huge changes: however, policies need not only a vision, but precise and mandatory goals, measurable impacts, and large investments. Involving European citizens in achieving a climate-neutral continent means shifting power from lobbies to communities, establishing common deliberative processes that municipalities can use in every European country in order to develop local mitigation strategies.

\section{REFERENCES}

[1] Masson-Delmotte, V. et al. (eds), Summary for policymakers, global warming of $1.5^{\circ} \mathrm{C}$ : An IPCC special report on the impacts of global warming of $1.5^{\circ} \mathrm{C}$ above preindustrial levels and related global greenhouse gas emission pathways, in the context of strengthening the global response to the threat of climate change, sustainable development, and efforts to eradicate poverty, IPCC. https://www.ipcc.ch/sr15/ chapter/spm/. Accessed on: 26 Apr. 2021.

[2] European Commission, Communication from the Commission to the European Parliament, the Council, the European Economic and Social Committee and the Committee of the Regions, European Climate Pact: Brussels, 2020.

[3] European Mission Board on Climate-neutral and smart cities, 100 climate-neutral cities by 2030 - by and for the citizens. Report of the Mission Board, 2020.

[4] United Nations, Department of Economic and Social Affairs, Population Division, World Urbanisation Prospects 2018: Highlights (ST/ESA/SER.a/421), 2019.

[5] European Parliament, Special Eurobarometer 490, Climate Change, 2019.

[6] European Mission Board on Climate-neutral and smart cities, 100 climate-neutral cities by 2030 - by and for the citizens. Report of the Mission Board, 2020.

[7] European Parliament, Special Eurobarometer 490, Climate Change, 2019.

[8] European Commission, Communication from the Commission to the European Parliament, the European Council, the Council, the European Economic and Social Committee of the Regions and the European Investment Bank. A Clean Planet for all - a European Strategic Long-Term Vision for a Prosperous, Modern, Clean, Competitive and Climate Neutral Economy (COM (2018) 773 Final), 2018. 
[9] European Commission, European Climate Law. https://ec.europa.eu/clima/policies/ eu-climate-action/law_en. Accessed on: 22 Apr. 2021.

[10] European Commission, Communication from the Commission to the European Parliament, the Council, the European Economic and Social Committee and the Committee of the Regions, European Climate Pact: Brussels, 2020.

[11] European Parliament, European Parliament Resolution of 16 Nov. 2017 on the EU Environmental Implementation Review (2018/C 356/14), 2018.

[12] European Commission, Communication from the European Commission to the European Parliament, the Council, the European Economic and Social Committee and the Committee of the Regions, Forging a Climate-resilient Europe - the new EU Strategy on Adaptation to Climate Change, Brussels, 2021.

[13] European Commission, Communication from the Commission to the European Parliament, the Council, the European Economic and Social Committee and the Committee of the Regions, Stepping up Europe's 2030 Climate Ambition. Investing in Climate-Neutral Future for the Benefit of our People, Brussels, 2020.

[14] Informal Ministerial Meeting on Urban Matters, The New Leipzig Chapter Adopted on 30 Nov. 2020.

[15] European Commission, New European Bauhaus, 2021.

[16] Statement by Ursula von der Leyen on the occasion of the launch of the design phase of the New European Bauhaus. https://europa.eu/!RQ49Gv, Accessed on: 14 Apr. 2021.

[17] European Commission, Signatories' Commitments. https://www.covenantofmayors.eu/about/covenant-initiative/objectives-andscope.html. Accessed on: 26 Apr. 2021.

[18] European Commission, Green City Accord. Clean and Healthy Cities for Europe, 2021.

[19] European Commission, What are the EU Missions? https://ec.europa.eu/info/horizoneurope/missions-horizon-europe_en. Accessed on: 27 Apr. 2021.

[20] Hanna Gronkiewicz-Waltz, Chair of the Mission Board for Climate Neutral and Smart Cities. Report of the Mission Board, Sep. 2020.

[21] European Commission, 100 Climate-neutral cities by 2030 - by and for the Citizens. Report of the Mission Board, 2020.

[22] Arnstein, S.R., A ladder of citizen participation. Journal of the American Institute of Planners, 35(4), pp. 216-224, 1969. 